\title{
Correction to: The diagnosis and treatment of urogenital schistosomiasis in Italy in a retrospective cohort of immigrants from Sub-Saharan Africa
}

Marta Tilli ${ }^{1} \cdot$ Federico Gobbi ${ }^{2} \cdot$ Francesca Rinaldi $^{1} \cdot$ Jacopo Testa $^{2,3} \cdot$ Silvio Caligaris $^{4} \cdot$ Paola Magro ${ }^{4}$. Dora Buonfrate $^{2}$. Monica Degani ${ }^{2} \cdot$ Andrea Minervini $^{1,5} \cdot$ Marco Carini $^{1,5} \cdot$ Agostino Tuccio $^{5} \cdot$ Simone Sforza ${ }^{1,5}$. Maurizio Gulletta ${ }^{4}$. Francesco Castelli ${ }^{4,6} \cdot$ Simone Agostini $^{7} \cdot$ Filippo Parretti $^{7}$. Joachim Richter ${ }^{8}$. Piero Olliaro ${ }^{9,10}$. Zeno Bisoffi ${ }^{2,11} \cdot$ Alessandro Bartoloni $^{1,12,13}$ (1) $\cdot$ Lorenzo Zammarchi ${ }^{1,12,13}$

Published online: 4 March 2019

(c) Springer-Verlag GmbH Germany, part of Springer Nature 2019

\section{Correction to: Infection}

https://doi.org/10.1007/s15010-019-01270-0

The original version of this article unfortunately contained a mistake. The given name and family name of Filippo Parretti was transposed in the original publication. The correct name is as shown above.

The original article has been corrected.

The original article can be found online at https://doi.org/10.1007/ s15010-019-01270-0.

Lorenzo Zammarchi

lorenzo.zammarchi@unifi.it

Extended author information available on the last page of the article 


\section{Affiliations}

\section{Marta Tilli ${ }^{1}$ - Federico Gobbi ${ }^{2}$. Francesca Rinaldi ${ }^{1} \cdot$ Jacopo Testa $^{2,3} \cdot$ Silvio Caligaris $^{4}$ - Paola Magro ${ }^{4}$. Dora Buonfrate $^{2} \cdot$ Monica Degani $^{2} \cdot$ Andrea Minervini $^{1,5} \cdot$ Marco Carini $^{1,5} \cdot$ Agostino Tuccio $^{5} \cdot$ Simone Sforza $^{1,5}$. Maurizio Gulletta ${ }^{4}$. Francesco Castelli ${ }^{4,6} \cdot$ Simone Agostini $^{7} \cdot$ Filippo Parretti $^{7} \cdot$ Joachim Richter $^{8} \cdot$ Piero Olliaro $^{9,10}$. Zeno Bisoffi, $^{2,11}$. Alessandro Bartoloni ${ }^{1,12,13}$ (D) . Lorenzo Zammarchi ${ }^{1,12,13}$}

\author{
Marta Tilli \\ marta.tilli@unifi.it \\ Federico Gobbi \\ federico.gobbi@sacrocuore.it \\ Francesca Rinaldi \\ francescarinaldi16@yahoo.it \\ Jacopo Testa \\ iltesta69@yahoo.it \\ Silvio Caligaris \\ silviocaligaris@yahoo.it \\ Paola Magro \\ magropao@gmail.com \\ Dora Buonfrate \\ dora.buonfrate@sacrocuore.it \\ Monica Degani \\ monica.degani@sacrocuore.it \\ Andrea Minervini \\ andrea.minervini@unifi.it \\ Marco Carini \\ marco.carini@unifi.it \\ Agostino Tuccio \\ agostinotuccio@yahoo.it \\ Simone Sforza \\ simone.sforza1988@gmail.com \\ Maurizio Gulletta \\ m.gulletta@infettivibrescia.it \\ Francesco Castelli \\ francesco.castelli@unibs.it \\ Simone Agostini \\ agostini.s@alice.it \\ Filippo Parretti \\ filiparre@yahoo.it \\ Joachim Richter \\ jockelri@gmail.com
}

Zeno Bisoffi

zeno.bisoffi@sacrocuore.it

Alessandro Bartoloni

alessandro.bartoloni@unifi.it

1 Department of Experimental and Clinical Medicine, University of Florence, Largo Brambilla 3, 50134 Florence, Italy

2 IRCCS Sacro Cuore Don Calabria Hospital, Negrar, Verona, Italy

3 Center for Clinical Ethics, Biotechnology and Life Sciences Department, Insubria University, Varese, Italy

4 University Department of Infectious and Tropical Diseases, University of Brescia and Spedali Civili General Hospital, Brescia, Italy

5 Department of Urology, Careggi University and Hospital, Florence, Italy

6 UNESCO Chair "Training and Empowering Human Resources for Health Development in Resource-Limited Countries, University of Brescia”, Brescia, Italy

7 Radiology Unit, Careggi University and Hospital, Florence, Italy

8 Institut für Tropenmedizin und Internationale Gesundheit Charité, Universitätsmedizin Berlin, Berlin, Germany

9 Special Programme for Research and Training in Tropical Diseases (TDR), World Health Organization, Geneva, Switzerland

10 Centre for Tropical Medicine and Global Health, Nuffield Department of Medicine, Oxford University, Oxford, UK

11 Department of Diagnostics and Public Health, University of Verona, Verona, Italy

12 Infectious and Tropical Diseases Unit, Careggi University and Hospital, Florence, Italy

13 Referral Center for Tropical Diseases of Tuscany, Infectious and Tropical Diseases Unit, Careggi University Hospital, Florence, Italy 